\title{
At the birth of pediatric anesthesia in Mexico: An interview with Dr. Estela Melman, a pioneering woman in medicine
}

\author{
Zulfiqar Ahmed ${ }^{1}$ (D) $\mid$ Christine Mai $^{2} \mid$ Katherine G. Skinner ${ }^{3} \mid$ Myron Yaster ${ }^{4}$
}

${ }^{1}$ Anesthesia Associates of Ann Arbor, Wayne State University, Detroit, Michigan

${ }^{2}$ Department of Anesthesia, Critical Care Medicine \& Pain Medicine, Massachusetts General Hospital, Harvard Medical School, Boston, Massachusetts

${ }^{3}$ Department of Anesthesiology, University of Michigan, Ann Arbor, Michigan

${ }^{4}$ Department of Anesthesiology, Children's Hospital Colorado, University of Colorado, Aurora, Colorado

\section{Correspondence}

Zulfiqar Ahmed, Anesthesia Associates of Ann Arbor, Wayne State University, Detroit, MI.

Email: zahmedz@yahoo.com

Funding information

Support was provided solely from

institutional and/or departmental sources.

Section Editor: Podcast Podcast

\begin{abstract}
Summary
Dr. Estela Melman (1939-present), Professor in the Department of Anesthesiology, the American British Cowdray Medical Center, Mexico, is an influential pioneer who has shaped the scope and practice of pediatric anesthesia in Mexico and throughout the world. Her early work to reintroduce neural blockade into routine pediatric anesthetic care, particularly the caudal approach to the epidural space, helped to transform current anesthesia practice. Based on a series of interviews held with Dr. Melman between 2016 and 2017, this article reviews the remarkable career of a pioneering pediatric anesthesiologist.
\end{abstract}

\section{KEYWORDS}

caudal anesthesia, Estela Melman, history of anesthesia, pediatric anesthesiology, regional anesthesia

\section{1 | INTRODUCTION}

You must step down from your position as the chief of pediatric anesthesia because you are occupying the position of a 'true' Mexican. You are a Jew and a woman ... Jews have a lot of money, why are you working here?

Over a career that spanned almost 50 years, Dr. Estela Melman pioneered the modern practice of pediatric anesthesia in Mexico and inspired a generation of anesthesiologists, pediatricians, and surgeons. Despite her national and international reputation as an exceptional leader, program builder, innovator, teacher, and master clinician, she was relieved of her duties as the chief of pediatric anesthesia at the Hospital Infantil de México (Children's Hospital of Mexico City) by the Mexican Minister of Health because of her gender and religion. This article chronicles her influence on and transformation of pediatric anesthesia in Mexico and abroad. It highlights the career of one of our specialty's founding mothers, including the environment in which she came of age, how she dealt with gender and religious bias, and the impact she has had on our profession.

\section{BACKGROUND HISTORY}

Estela Melman (Figure 1) was born in Mexico City, Mexico, in 1939 to Jewish parents who met in Mexico during the years between the two world wars. Her parents had escaped the poverty and antisemitism of Europe, conditions that ultimately led to the holocaust when Adolf Hitler rose to power in Germany. Having been denied entrance to the United States, they found in Mexico a welcoming and accommodating country where they could maintain their own identity and raise a family in safety and comfort. A traditional family, Melman's father was a businessman and her mother a housewife who devoted herself to her husband and three daughters.

Melman decided to become a doctor at the age of 12 when she developed acute rheumatic fever and was confined to her bed for 3 months. Her pediatrician, Dr. Morris Hoffs, was a kind and imposing figure who convinced her to follow in his footsteps and become 
a doctor. While in medical school she met her husband, Guillermo, and together they came to the United States for postgraduate medical education. Although she had planned to become a pediatrician and emulate her idol, Dr. Hoffs, she discovered anesthesiology during a particularly boring surgical procedure while on her rotating internship at the Sinai Hospital in Detroit. She found surgery boring, she said, because "my primary job was to hold retractors and there was no teaching." However, while holding retractors, she would lean back and listen to the director of the anesthesia department, Dr. Eli Brown, as he taught his students pharmacology, physiology, and pathophysiology as it applied to the patient who was undergoing surgery. Fascinated, she set out to become an anesthesiologist and was accepted by Dr. Brown into Sinai's residency program. He became her chairman and mentor and encouraged her to apply to the University of Pennsylvania for an anesthesia research fellowship under the legendary Dr. Robert D. Dripps (Figure 2).

In what would become a lifelong battle, she had to overcome enormous obstacles to get this position. Dripps did not want her because, as he told Melman in her fellowship interview, "women get pregnant and abandon their training programs and careers." However, she refused to back down, telling him "that this was not going to happen to me." He then asked her "are you going to return to Mexico once you finish?" When she responded in the affirmative, Dripps told her that this was another reason not to accept her because "in Mexico, no one moves upward without strong political connections, which you do not have." Again, she did not back down and responded that the same could be said of the US and asked him "if my last name was 'Kennedy' would you accept me?" Impressed by her grit and moxie, Dripps immediately accepted her into his program.

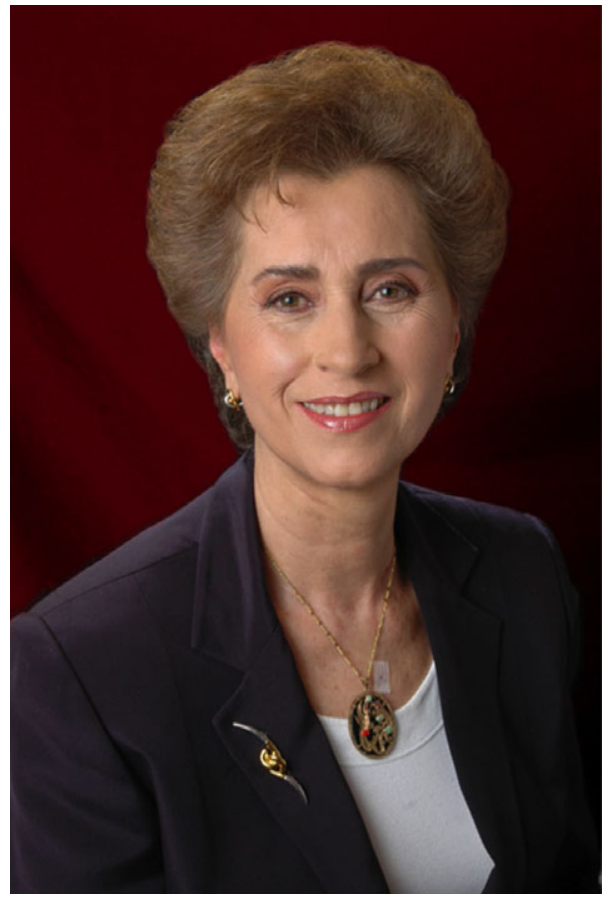

FIGURE 1 Dr. Estela Melman. Photo courtesy of Dr. Melman, 2018 [Colour figure can be viewed at wileyonlinelibrary.com]
During her 2-year research fellowship, Melman worked with several of the giants in the field and published several papers with Drs. Harry Wollman, S. Craighead Alexander, Peter Cohen, Patricia Chase, and Robert Dripps in various journals, including Anesthesiology. ${ }^{1,2}$ She also worked with legendary anesthesiologist Dr. James Eckenhoff (Figure 3) on deliberate hypotension and presented their research results at The New York Academy of Sciences. Their findings were published in the Annals of The New York Academy of Sciences. $^{3}$

During her research fellowship, Melman remained determined to return to Mexico to practice pediatric anesthesia. Because her exposure to pediatric anesthesia in Detroit was limited, she asked and received permission from Dripps and Dr. Leonard Bachman, chief of pediatric anesthesia at the Children's Hospital of Philadelphia (CHOP), to do an advanced clinical rotation (fellowship) in pediatric anesthesia at CHOP. In the 1960s and 1970s, American anesthesia

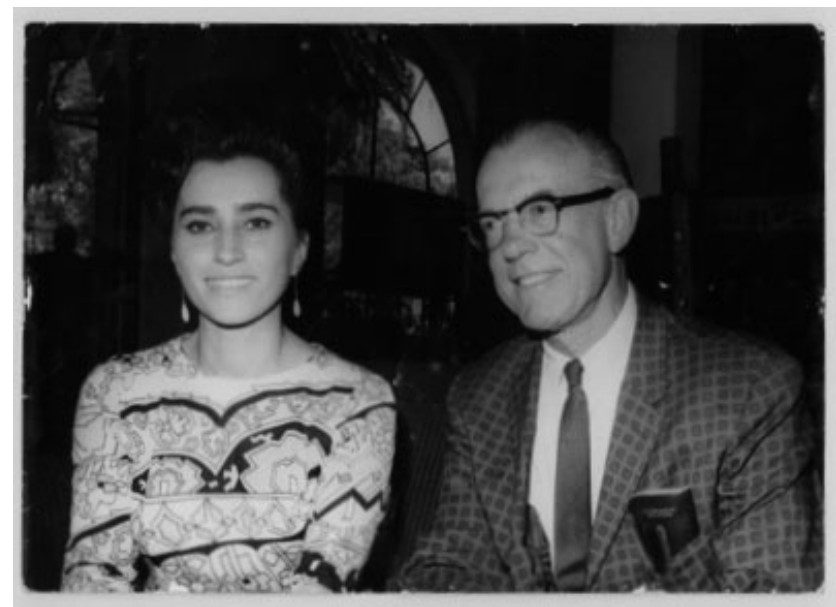

FIGURE 2 Dr. Melman with Dr. Robert D. Dripps during his educational visit to Mexico. Photo courtesy of Dr. Melman

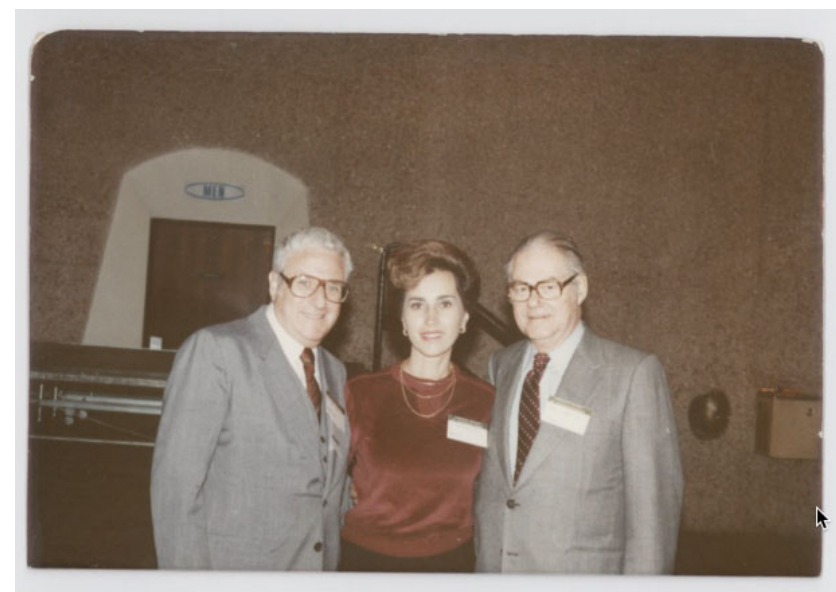

FIGURE 3 Dr. Melman (center) in 1980 with Dr. James Eckenhoff (left) and Dr. Eli Brown (right) at a meeting of the American Society of Anesthesiologists. Photo courtesy of Dr. Melman [Colour figure can be viewed at wileyonlinelibrary.com] 
residencies were only 2 years, and clinical fellowships were an ad hoc affair that lasted 3-6 months. Pediatric anesthesia as a distinct subspecialty was in its infancy and claimed only a handful of fellowship programs in North America. Melman was among the first women to train in the nascent subspecialty.

The practice of pediatric anesthesia at that time bears little resemblance to current (2018) practice. Indeed, it can be difficult to fathom just how primitive and dangerous anesthesia was in general, and pediatric anesthesia in particular, when she entered the field. In the 1960s and 1970s, little was known about pediatric and neonatal pharmacology and physiology. Intraoperative monitoring was rudimentary, consisting of little more than a precordial stethoscope, keen eyes, steely nerves, and finely honed clinical acumen. Hemodynamic monitoring was not optimized for infants and children, and measuring blood pressure was a tour de force, performed manually with a blood pressure cuff and stethoscope while listening for changes in Korotkoff sounds or the presence or absence of Doppler probe flows. Even finding appropriately sized blood pressure cuffs was a challenge, particularly for small children. Perhaps not surprisingly, perioperative death was common, even in healthy infants with ASA physical status 1 and $2 .^{4}$

Nevertheless, during the 1960s and 1970s, the period when Melman came of professional age, profound changes were occurring that revolutionized the profession. Laryngoscopy blades and endotracheal tubes for infants that were developed in the late 1920s-1940s became readily available and widely used. ${ }^{5,6}$ Mechanical ventilation, blood gas analysis, and pediatric and neonatal care units were being developed. ${ }^{7,8}$ Resuscitation techniques for both adults and children made survival possible after cardiopulmonary collapse. And yet when she arrived as a young, newly minted specialist in pediatric anesthesia at the Hospital Infantil de México "Federico Gomez" (Children's Hospital in Mexico City), she was shocked by what she found. The staff were inadequately trained, morale was low, and the most basic equipment necessary to provide modern and safe anesthesia was lacking, out of date, or broken. Indeed, during her first year back in Mexico, there were many times that she despaired and considered returning to practice in America. After talking to her husband, Dr. Guillermo Bierzwinsky, they decided that their mission was to stay in Mexico and improve conditions at the hospital and country through education, quality clinical care, and research. She fought to improve conditions in Mexico with the leadership skills she had learned from her mentors, Brown, Dripps, and Eckenhoff. She realized almost immediately that the key to improving pediatric anesthetic care was to improve the quality and training of its practitioners. When she initiated the first fellowship training program in pediatric anesthesia in Mexico, students came not just from within Mexico, but from South and Central America as well. Her personal qualities inspired extraordinary loyalty, devotion, and respect, and not just because of the training program she created and directed. Rather, it was largely due to her kindness, humanity, generosity, and vision of what a professional pediatric anesthesiologist and intensivist should be. She trained several generations of pediatric anesthesiologists and eventually rose to become the chief of the department of anesthesiology at the Hospital Infantil de México.

In those early days, besides improving conditions at the hospital and teaching residents and fellows, she was also actively involved in research and scholarly activities. Her most important pioneering work involved regional anesthesia in children. ${ }^{9}$ Although the first successful spinal anesthesia was performed in an 11-year old by August Bier in $1898,{ }^{10}$ and the first caudal anesthesia was performed in $1933,{ }^{11}$ in the mid-20th century, US doctors rarely performed regional anesthesia in children. ${ }^{12}$ Working initially in a cadaver laboratory to determine the doses of local anesthetic needed to achieve satisfactory dermatomal spread, and then with children in IRB-approved research trials, Melman et al ${ }^{9,13}$ was among the first to demonstrate the effectiveness of neural blockade, particularly the caudal approach to the epidural space, in pediatric anesthesia. Indeed, her original study was met with substantial skepticism and was rejected by one of the editors at Anesthesia and Analgesia. According to Melman, the editor wrote that "regional anesthesia in pediatrics would never be accepted in the United States nor any of the developed countries and would be of interest only in underdeveloped countries like Mexico." Fortunately, others on the editorial board disagreed and the published manuscript revolutionized care, making pediatric regional anesthesia ubiquitous throughout the world. Melman continues to be an active proponent of regional anesthesia. She is involved in local and international efforts to promote the teaching of regional anesthesia and to educate practitioners on how to incorporate it into daily practice and consider the pros and cons of peripheral vs central neural blockade. ${ }^{14}$

Like many of the pioneers in pediatric anesthesiology, Melman was involved in the development of pediatric respiratory and intensive care, ${ }^{7,8,15,16}$ although in her case, this happened serendipitously. When she arrived in Mexico, the Hospital Infantil de México did not have positive-pressure ventilators and still relied on negative-pressure ventilators that were used in the polio epidemics of the 1940s1950s. One day, while walking through the cardiovascular section of the hospital, she found an unopened box in a closet that contained a Mark $\mathrm{V}$ ventilator. It had been donated to the cardiovascular surgery department but had remained in its original packing crate because no one knew how to use it. Much to the surprise and chagrin of her colleagues and hospital administrators, she began using the ventilator, which she had used previously in the US. Initially, the single ventilator was used intra- and postoperatively and later for medical and surgical patients in respiratory distress. Soon the results "spoke for themselves." She obtained more positive-pressure ventilators, expanded their use to infants and newborns, and created the department of respiratory therapy, which served the medical and surgical population of the entire hospital. Indeed, she considers the establishment of a 24/7 respiratory therapy medical department one of her greatest and most enduring accomplishments.

Establishing a tracheal airway is fundamental to the practice of anesthesiology. In some patients with congenital or acquired malformations of the head, face, and neck, standard techniques of direct laryngoscopy may be difficult or impossible. Because the Hospital 
Infantil de México is a regional and national center for pediatrics, patients with unusual and complicated airways are common and, according to Melman, "amongst the most difficult tasks I faced." At the time, the only alternative to direct laryngoscopy was rigid direct laryngoscopy or tracheostomy by the surgeon. Working with a surgeon named Fernando Ortiz Monasterion, she created a craniofacial anesthesia service and was among the first to use fiberoptic intubation as an alternative in the difficult pediatric airway. ${ }^{17}$ Further, because the loss of airway patency can occur rapidly, producing hypoxemia, she pioneered the use of supplemental oxygen and atropine (to prevent bradycardia and dry secretions) to ensure the success of this technique. Based on her skills and experience, Melman has participated in difficult airway workshops of the American Society of Anesthesiologists, the Society for Pediatric Anesthesia, and the Mexican Society of Anesthesiologists.

Since her earliest years in practice, Melman has resisted the status quo and worked tirelessly to improve the safety of delivering anesthesia to the children of Mexico. She introduced pulse oximetry, capnography, and intracranial pressure monitoring to her practice, often over the resistance of her colleagues and hospital administrators. Several of her colleagues insisted on assessing a patient's status by the color change of the patient, rather than with a pulse oximeter. They would proudly proclaim that "the patient is less blue or less red or more pinkish." She challenged them by asking "how can one accurately tell the oxygenation and saturation of the patient by naked eye, if one could measure it?"

Besides working in her institution, she was deeply involved with the creation of the Mexican Society of Anesthesia (now the Mexican College of Anesthesiologists), which is part of the World Federation of Societies of Anesthesia (WFSA), ultimately rising to its presidency. Indeed, she is the only person to have served a 3-year term as president of the society, and she remains the coordinator of its scientific committee. Additionally, Melman is the founder and current president of the Mexican National Board of Certification in Anesthesia, which is equivalent to the American Board of Anesthesiology. Finally, she is an advisor to the Medical and Scientific Board of Directors of the Institute for Social Security for Government Workers (ISSSTE) in Mexico.

The authors wish that her many accomplishments and great successes would allow us a happy ending. Alas, it does not. Despite her achievements and 25 years of service as the chief of pediatric anesthesia, in 1989, the then Mexican Minister of Health, Dr. Jesús Kumatei, who was formerly a pediatrician and a director at the hospital, asked her to step down from her position. "You must step down from your position as the chief of pediatric anesthesia because you are occupying the position of a 'true' Mexican. You are a Jew and a woman ... Jews have a lot of money, why are you working here?" From his perspective these flaws made her unqualified for the position. The medical director of the hospital did not want her to leave and asked her to stay in the department but not as its chief. She refused out of principle and said that she "didn't deserve such indignities" and proceeded to resign and go into private practice. To this day, she continues in practice as a professor of pediatric anesthesia in the Department of Anesthesia at the American British Cowdray Medical Center and the Hospital Ángeles in Mexico City. She also mentors young anesthesiologists and writes prolifically for medical journals in Mexico and abroad.

\section{3 | PROFESSIONAL SOCIETIES}

Aside from her leadership roles in the Mexican College of Anesthesiologists and the National Board of Certification in Anesthesia, she is a member of the Mexican National Academy of Medicine (Academia Nacional de Medicina), the Mexican Academy of Pediatrics (Academia Mexicana de Pediatría), the Federation of Mexican Colleges of Anesthesiologists (part of the WFSA), and the Mexican Society for Pediatric Anesthesiologists. Finally, she is a member of the American Academy of Pediatrics, the American Society of Anesthesiologists, the American Society of Regional Anesthesia and Pain Medicine, and a founding member of the Society for Pediatric Anesthesia.

\section{4 | FAMILY}

No discussion of Melman's career would be complete without discussing her close-knit family. Throughout her distinguished career, she has been supported in the pursuit of her professional ambitions by her wonderful husband, Guillermo (Figure 4), an internist, gastroenterologist, and former Director of Drug Administration at the Mexican Ministry of Health (equivalent to the US Food and Drug Administration), her three children-Becky, a dentist; Mauricio, an industrial engineer; and Raquel, a lawyer-and her five grandchildren. She feels indebted to all of them because, as she said, "medicine was my 'calling' and I wasn't always there for them." Her priorities were to her patients, to her profession, and to the advancement of pediatric and general anesthesia practice in Mexico.

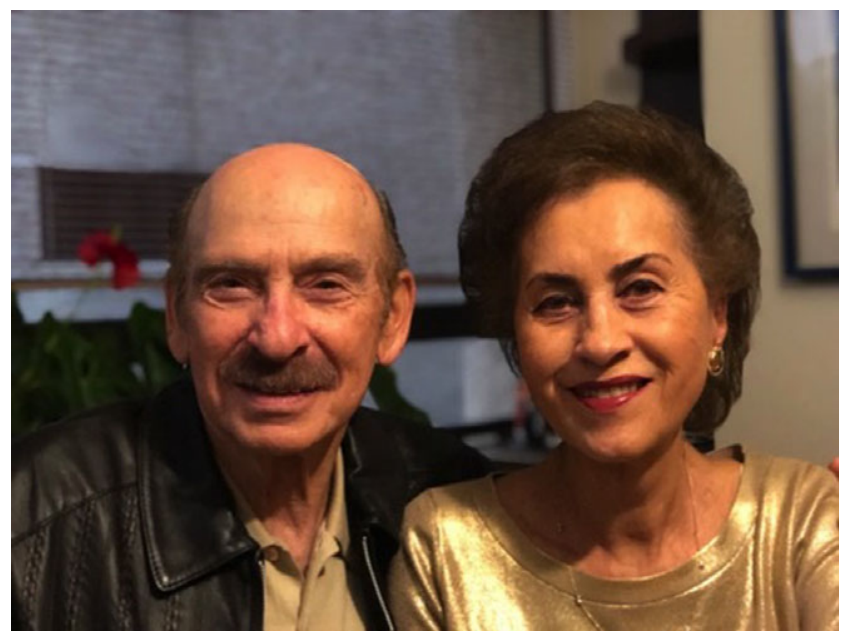

FIG URE 4 Dr. Melman with her husband Dr. Guillermo Bierzwinsky 2018. Photo courtesy of Dr. Melman [Colour figure can be viewed at wileyonlinelibrary.com] 


\section{5 | CONCLUSIONS}

Estela Melman is an influential pioneer in the history of pediatric anesthesia, having shaped the scope and practice of pediatric anesthesia in Mexico and throughout the world. Her clinical research helped reintroduce neural blockade, particularly the caudal approach to the epidural space, into routine pediatric anesthetic care and has transformed the current practice of anesthesia. Please include see Video S1 for a personal narrative by Dr. Melman. Among her countless other contributions, she helped to establish pediatric anesthesia as the specialty we practice today.

\section{ETHICAL APPROVAL}

No IRB approval was needed.

\section{DISCLOSURES}

The authors report no conflict of interest.

\section{ORCID}

Zulfiqar Ahmed iD http://orcid.org/0000-0002-0331-502X

\section{REFERENCES}

1. Alexander SC, Wollman $\mathrm{H}$, Cohen PJ, et al. Krypton- 85 and nitrous oxide uptake of the human brain during anesthesia. Anesthesiology. 1964;25:37-42.

2. Wollman H, Alexander SC, Cohen PJ, et al. Cerebral circulation of man during halothane anesthesia: effects of hypocarbia and of d-tubocurarine. Anesthesiology. 1964;25:180-184.

3. Eckenhoff JE, Melman E. Deliberate hypotension in the control of operative bleeding. Ann N Y Acad Sci. 1964;115:341-347.

4. Rackow H, Salanitre E, Green LT. Frequency of cardiac arrest associated with anesthesia in infants and children. Pediatrics. 1961;28:697704.

5. Chodoff $P$, Helrich $M$. Factors affecting pediatric endotracheal tube size: a statistical analysis. Anesthesiology. 1967;28:779-782.

6. Cole F. An endotracheal tube for babies. Anesthesiology. 1945;6:627.
7. Mai $C L$, Yaster M, Firth $P$. The development of continuous positive airway pressure: an interview with Dr. George Gregory. Pediatr Anesth. 2013;23:3-8.

8. Mai CL, Schreiner MS, Firth PG, et al. The development of Pediatric Critical Care Medicine at The Children's Hospital of Philadelphia: an interview with Dr. John J. 'Jack' Downes. Pediatr Anesth. 2013;23:655-664.

9. Melman E, Penuelas JA, Marrufo J. Regional anesthesia in children Anesth Analg. 1975;54:387-390.

10. Bier A. Experiment regarding the cocainization of the spinal cord. Zentralbl Chir. 1899;51:361-369.

11. Campell MF. Caudal anesthesia in children. Am J Urol. 1933;30:245249.

12. Brown TC. History of pediatric regional anesthesia. Pediatr Anesth. 2012;22:3-9.

13. Melman E, Arenas JA, Tandazo WE. Caudal anesthesia for pediatric surgery. An easy and safe method for calculating dose requirements. Anesthesiology. 1985;63:3A, 463.

14. Marhofer P, Ivani $G$, Suresh $S$, et al. Everyday regional anesthesia in children. Pediatr Anesth. 2012;22:995-1001.

15. Mai CL, Firth PG, Ahmed Z, et al. The development of a specialty: an interview with Dr. Mark C. Rogers, a pioneering pediatric intensivist. Pediatr Anesth. 2014;24:912-918.

16. Ahmed Z, Samuels PJ, Mai CL, et al. The development of pediatric anesthesiology and critical care medicine at the Cincinnati Children's Hospital: an interview with Dr. Theodore Striker. Pediatr Anesth. 2015;25:764-769.

17. Blanco G, Melman E, Cuairan V, et al. Fibreoptic nasal intubation in children with anticipated and unanticipated difficult intubation. Paediatr Anaesth. 2001;11:49-53.

\section{SUPPORTING INFORMATION}

Additional supporting information may be found online in the Supporting Information section at the end of the article.

How to cite this article: Ahmed Z, Mai C, Skinner KG, Yaster $M$. At the birth of pediatric anesthesia in Mexico: An interview with Dr. Estela Melman, a pioneering woman in medicine. Pediatr Anesth. 2018;28:1066-1070.

https://doi.org/10.1111/pan.13518 